
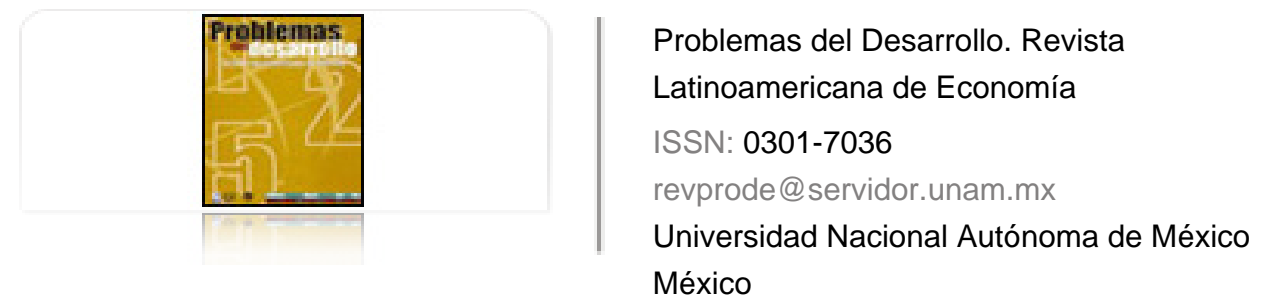

Rodríguez y Rodríguez, Ma. Teresa

INGRESO DE CHINA A LA ORGANIZACIÓN MUNDIAL DE COMERCIO. SU PRIMER IMPACTO SOBRE EL COMERCIO MUNDIAL

Problemas del Desarrollo. Revista Latinoamericana de Economía, vol. 34, núm. 134, 2003, pp. 49-73

Universidad Nacional Autónoma de México

Distrito Federal, México

Disponible en: http://www.redalyc.org/articulo.oa?id=11825944004

Cómo citar el artículo

- Número completo

- Más información del artículo

Página de la revista en redalyc.org

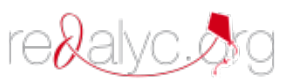

Sistema de Información Científica

Red de Revistas Científicas de América Latina, el Caribe, España y Portugal Proyecto académico sin fines de lucro, desarrollado bajo la iniciativa de acceso abierto 


\title{
Ingreso de China a la Organización Mundial de Comercio. Su PRIMER IMPACto SOBRe El COMERcio
}

\author{
MUNDIAL
}

\section{Ma. Teresa Rodríguez y Rodríguez*}

Fecha de recepción: 7 de enero de 2003. Fecha de autorización: 17 de noviembre de 2003.

\begin{abstract}
Resumen
El ingreso reciente de la República Popular China a la Organización Mundial de Comercio (омC) ha causado revuelo a nivel internacional, tanto por el gran peso específico de esa nación, como por su rápida inserción en las corrientes mundiales de comercio. Existen diferencias reales y de percepción según el país: para Estados Unidos y la Unión Europea, aunque con enormes déficit comerciales frente a China, se les abren oportunidades en sectores anteriormente cerrados (agropecuario, telecomunicaciones, financiero). En cambio, México y otros exportadores de manufacturas de industria ligera temen la incursión creciente de los productos chinos en los mercados de naciones avanzadas, principalmente en el estadounidense. El avance de esta república se produjo antes de su ingreso a la OMC, así es que ahora, también para países como el nuestro, el camino es tratar de aprovechar mejor la creciente apertura del mercado de este territorio.
\end{abstract}

Palabras clave: China, омC, apertura y reforma, liberalización comercial, competitividad internacional.

\begin{abstract}
The recent admission of the People's Republic of China to the World Trade Organization (WTO) has caused a storm internationally due to both China's great specific importance and its rapid incorporation into world trade. Each country has both real and perceived differences: in spite of the trade deficits with China in sectors that used to be closed: agriculture, telecommunications, finances, new opportunities are opening up for the United States and the European Union. However, exporters of light industrial manufactured goods, like Mexico, fear the increasing admission of Chinese products to the markets of advanced countries, mainly the United States. Key words: China, wTO, economic liberalization and reform, trade liberalization, international competitiveness.
\end{abstract}

* Investigadora Asociada "C" de Tiempo Completo Definitivo en el Instituto de Investigaciones Económicas (IIEC-UNAM). Correo electrónico: tmaria@servidor.unam.mx y anguiano@mexis.com 


\section{Résumé}

La récente entrée de la République Populaire Chinoise dans l'Organisation mondiale du commerce (OMC) a semé une grande agitation à l'échelle internationale, due autant au poids spécifique de cette nation qu'à sa rapide insertion dans les courants mondiaux de commerce. Il existe des différences réelles et de perception selon le pays: les États-Unis et l'Union européenne, bien qu'avec d'énormes déficits commerciaux face à la Chine, voient s'ouvrir des opportunités dans des secteurs auparavant fermés (agriculture, télécommunications, finance). Par contre, le Mexique et d'autres exportateurs de produits manufacturés d'industrie légère redoutent l'incursion croissante des produits chinois dans les marchés de pays développés, principalement celui des États-Unis.

Mots-cléfs: Chine, омC, ouverture et réforme, libéralisation commerciale, compétitivité internationale.

\section{Resumo}

A recente entrada da República Popular da China na Organização Mundial do Comércio (OMC) causou certa agitação a nível internacional não só pelo grande peso específico desse país, como pela sua rápida inserção nas correntes mundiais de comércio. Existem diferenças reais e de percepção segundo o país: para os Estados Unidos e a União Européia, embora com enormes déficits comerciais em face à China, abrem-se oportunidades em setores antes fechados (agropecuário, telecomunicações, financeiro). O México e outros exportadores de manufaturas de industria leve, entretanto, vêem com medo a incursão crescente dos produtos chineses nos mercados dos países avançados, principalmente no estadunidense.

Palavras chave: China, OMC, abertura e reforma, liberalização comercial, competitividade internacional. 


\section{Introducción}

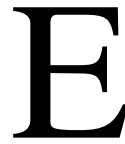

1 ingreso de la República Popular China a la Organización Mundial de Comercio (OMC) en diciembre de 2001 — después de haberse completado en noviembre de ese año (wTo, noviembre de 2001:3) los procedimientos requeridos por dicho organismo para su entrada - ha causado revuelo en los medios internacionales. Primero, por tratarse de un acontecimiento largamente anunciado que finalmente se materializó, pero más todavía porque se le interpreta como la entrega, a ese país, de una llave maestra a los mercados de los demás miembros de la organización.

En materia de manejo de su comercio exterior, debemos aclarar que China no es un sistema monolítico que de un día para otro se insertó en los mercados internacionales, sino una nación con un gran peso específico a nivel mundial, ${ }^{1}$ que hace poco más de dos décadas comenzó su apertura gradual al comercio y a la inversión extranjeras y que, a partir de una todavía mayor participación en las corrientes de comercio mundial, consecuente con su entrada a la OMC, provocará desajustes a corto y mediano plazos en las economías de sus socios comerciales, sobre todo de aquellos con los que compite más estrechamente.

En cuanto a los efectos de esa apertura sobre su economía interna, cabe recordar que China está pasando por un periodo de transición en varios ámbitos de la actividad humana como la economía, la demografía, los hábitos de consumo, lo cual la hace vulnerable a los cambios en la situación internacional; o sea, que también se verá afectada, positiva y negativamente, por su participación cada vez más activa en el comercio mundial.

La República Popular China comenzó a abrirse al exterior a principios de los años ochenta y aunque en muchos aspectos lo hizo de manera más cautelosa que países en desarrollo no socialistas, como México, en otros ha ido más rápido, por ejemplo al permitir la participación del capital extranjero en el desarrollo de sus hidrocarburos. En cuanto a los mecanismos con ayuda de los cuales China maneja sus intercambios comerciales y económicos con el exterior, éstos también han experimentado grandes transformaciones, que desde luego tienen que ver con su creciente apertura, pero sobre todo con un afán de modernización y reestructuración de su sistema económico.

Es decir, que habría que tratar de ver a este país como un elemento renovador del comercio multilateral: al momento de su ingreso a la OMC los demás miembros de este

1 Tercer territorio más grande del planeta, que contiene $20.8 \%$ de la población mundial y cuyo PIB, calculado a la paridad del poder adquisitivo de la moneda de ese país, representa $12.7 \%$ de la economía global (FMI, abril de 2003:161). 
organismo se han visto obligados a revisar cuidadosamente la reglamentación derivada del Acuerdo General sobre Aranceles y Comercio (GATT, por sus siglas en inglés), ${ }^{2}$ debido a que resultaba insuficiente para evitar las restricciones no arancelarias al comercio multilateral. Por lo pronto, China tendrá que hacer más transparentes sus operaciones de comercio con el exterior, lo que representa una ventaja respecto a la situación previa a su ingreso.

En lo relativo a la cooperación dentro de la omc, el ingreso de esa República Popular a la organización podría resultar en apoyo para los demás países en desarrollo (PED) dentro de la misma, por lo menos en lo concerniente a un mayor poder de negociación conjunto. La primera muestra de ese potencial se vio en la fracasada reunión ministerial de la OMC en Cancún, en septiembre de 2003, cuando un grupo, al frente del cual se encontraban Brasil, China e India, logró frenar a los países desarrollados en su intento por alcanzar acuerdos favorables a sus productos y servicios, pero contrarios a la liberalización de los productos primarios.

En este artículo me referiré, en primer lugar, al nacimiento del GATT, del cual China - todavía no socialista - fue parte integral desde el inicio, e inmediatamente después abordaremos la evolución de ese acuerdo en lo referente a la aceptación de países socialistas en su seno; más adelante, haré hincapié en el hecho de que el ingreso a la OMC a fines de 2001 no es gratuito, sino resultado del esfuerzo gradual de ese nación por ajustarse a las reglas del comercio multilateral a lo largo de, por lo menos, quince años (incisos sobre cambios institucionales y liberalización de aranceles, evolución del papel del Estado en el manejo del comercio exterior, entre otros).

Más todavía, me parece que China está pagando un precio más alto que el cubierto por otros países socialistas al momento de su ingreso al GATT (incisos sobre condiciones impuestas a esa República Popular para su ingreso a la OMC, a partir de la negociación sinoestadounidense y la habida entre China y la Unión Europea), que sus autoridades han aceptado, entre otras razones, porque consideran que esa membresía es parte integral de su estrategia de modernización económica y apertura al exterior.

\section{Nacimiento del GATT y el caso particular de la participación de China en ese Acuerdo}

El Acuerdo General sobre Aranceles y Comercio fue el subproducto de la frustrada Organización Internacional de Comercio (OIC), que se intentó crear en el seno de las Naciones Unidas entre 1946 y 1948. Tensiones generadas por el inicio de la Guerra Fría ${ }^{3}$ impidieron

2 El acuerdo General sobre Aranceles y Comercio entró en vigor el 10. de enero de 1948, en Ginebra, Suiza, con 23 miembros fundadores entre los que estaban la República de China, Francia, Estados Unidos y Reino Unido (Keesing's, 1995:40386 y R148).

3 Aunque algunos historiadores marcan el verano de 1945 como el inicio de la Guerra Fría - con el discurso de W inston Churchill en M issouri, Estados Unidos, en el cual dijo queuna cortina dehierro 
la participación de la Unión Soviética y de sus principales satélites —Bulgaria, Rumania y Polonia- así como de otros regímenes comunistas surgidos de movimientos nacionales, como el albano y el yugoslavo, en ese propósito; pero el tiro de gracia a la oic provino de Estados Unidos, cuando el congreso de ese país se negó a ratificar la Carta de La Habana, constitutiva de la organización comercial internacional citada.

El proyecto de la segunda posguerra, de restaurar la economía mundial, impulsado principalmente por Estados Unidos y Gran Bretaña, contemplaba el funcionamiento tanto de las instituciones de Bretton Woods - Fondo Monetario Internacional (FMI) y Banco Internacional de Reconstrucción y Fomento (BM/BIRF)—, como de un tercer pilar, que iba a ser la oIC. Ante el fracaso en el intento de creación de esta última, veintitrés países no comunistas pusieron en marcha el GATT que, como su nombre lo indica, no constituía un tratado multinacional, sino un conjunto de reglas para promover negociaciones comerciales multilaterales que condujeran a la liberalización del comercio internacional.

Entre los miembros fundadores del GATT se hallaba la República de China, que desde 1927 había estado gobernada por el partido nacionalista, bajo el liderazgo del generalísimo Chiang Kai-Shek (1888-1975). Pero justo en los años 1948-1949, China estaba pasando por la última fase de una guerra civil entre ese gobierno y su opositor histórico, el partido comunista, encabezado por Mao Zedong (1893-1976), misma que a principios de 1949 se definiría a favor de éste.

El triunfo comunista y la inmediata creación de la República Popular China, el 1o. de octubre de 1949, hizo que se agudizara la pugna entre los bloques estadounidense y soviético en varios frentes, incluida la onU y otras instituciones internacionales. Dado el predominio de Estados Unidos en la diplomacia multilateral, durante los subsiguientes veintidós años, en las Naciones Unidas se reconoció como legítimo representante de China al gobierno de los nacionalistas, refugiado en la isla de Taiwan, de 36000 kilómetros cuadrados de superficie, y protegido militarmente por Washington, con lo cual se dejó fuera al de Beijing, a pesar de que este último ejercía el control real sobre los 9.6 millones de kilómetros cuadrados que tiene el territorio continental chino.

Pero la decisión tomada en el GATT con relación a China fue ligeramente distinta a la adoptada en las Naciones Unidas y su Consejo de Seguridad: la república en Taiwan dejó de ser integrante pleno del Acuerdo y pasó a ser observador. En octubre de 1971, ya con una diferente correlación de fuerzas políticas dentro de la onU, la República Popular recuperó el asiento de China en Naciones Unidas y sus agencias especializadas, entre las que estaba el GATT; así, en noviembre de 1971, la Asamblea de este órgano decidió por consenso privar a Taiwan de su estatus de observador, y otorgárselo a la República Popular. Habrían

separaba a las democracias de las dictaduras comunistas en Europa- Ios hechos quemarcan el inicio de tal conflicto son la llamada Doctrina Truman y el Plan M arshall, ambos anunciados en 1947. 
de pasar treinta años más, antes de que ésta se convirtiera en integrante con pleno derecho en la OMC, sucesora del GATT.

\section{Evolución del gatT en lo concerniente a la aceptación de economías socialistas en su seno}

A lo largo de los años, hasta su incorporación plena en la OMC en 1995, el GATT evolucionó tanto en lo relativo al número de sus integrantes como al ampliar sus objetivos, situación que lo llevó a permitir la participación de economías centralmente planificadas. Además, cabe señalar que uno de los requisitos para el ingreso de cualquier economía a la oMc, es que sus intercambios con el resto del mundo no sean llevados a cabo por un monopolio, estatal o privado. A partir de que se cumpla esa condición mínima, hay una gran diversidad de situaciones que son aceptadas al interior del organización.

Por lo pronto, China no es la primera nación de economía centralmente planificada o mixta, y con predominio de la propiedad pública de los medios de producción que llega a formar parte de ese organismo.

Como ejemplos previos, está el ingreso de Checoslovaquia al GATT a fines de los cuarenta como socio fundador - a pesar de que ya se había producido el virtual golpe de Estado de mayo de 1947, propiciado por la Unión Soviética, que puso a los checos bajo un régimen socialista y dentro del bloque soviético—. También lo fue el de Yugoslavia en 1966, país socialista que mantuvo una línea neutral en la confrontación bipolar de la época de la Guerra Fría; de Polonia en 1967- que no por ello dejó de ser parte del bloque comunista en sus dos instituciones básicas, el Consejo Económico de Asistencia Mutua y el Pacto de Varsovia; el de Rumania en 1971, bajo la dictadura de Nicolai Ceasescu (19181989), y de Hungría en 1973.

Después de la caída del muro de Berlín y del bloque socialista, que conllevó la desaparición de la Unión Soviética y la desintegración de Yugoslavia y Checoslovaquia, en 1993 ingresarían al GATT la República Checa y Eslovaquia; poco después, el 1o. de enero de 1995, fecha de entrada en vigor de la OMC, varias ex repúblicas soviéticas habrían de adherirse a dicho organismo.

En todo caso, la desaparición de los regímenes comunistas de Europa oriental propició que países históricamente opuestos al GATT negociaran su ingreso a la organización sucesora, tal es el caso de Bulgaria (1996).

Al 4 de abril de 2003, en la OMC había 146 integrantes y 30 observadores (wTO/GATT, Members and Observers, 2003). De estos últimos, Azerbaiyán, Bielorrusia, Kazajistán, Tayikistán, Ucrania, Uzbekistán y la propia Federación Rusa tenían estatus de acceso; es decir, estaban en negociaciones para ingresar a la OMC, al igual que Vietnam y Laos. Lo que resta de la antigua Yugoslavia, suspendida del GATT en junio de 1992, es ahora miem- 
bro observador también con el mismo estatus, pero Macedonia ya es integrante pleno (wTO/GATT, Members and Observers, 2003).

En cada ocasión, los gobiernos respectivos tuvieron que aceptar las condiciones que se les impusieron para permitirles el ingreso, desde luego, la de transparentar las actividades de sus organismos estatales o mixtos a cargo del comercio exterior y continuar con el proceso de liberalización comercial y económica que, en la mayoría de los casos, ya habían iniciado al momento de su adhesión al GATT o directamente a la omc. Adicionalmente, a algunos de estos países se les pidió que mantuvieran un cierto ritmo de crecimiento en sus importaciones, como mecanismo temporal para compensar el control altamente centralizado de sus transacciones comerciales con el exterior.

En la práctica, sin embargo, las condiciones acordadas entre estos países y la омc no han sido cabalmente cumplidas, ni se ha producido la liberalización inmediata y total del comercio por parte del resto de esa comunidad hacia sus nuevos integrantes. La realidad es que la reglamentación del GATT, actualmente integrada a los estatutos de la OMC, no logra prever las distintas situaciones que pueden presentarse con relación al intercambio multilateral; de manera tal que, para subsanar los efectos de posibles irregularidades en el cumplimiento de las reglas fijadas por el Acuerdo General, las economías establecen cortapisas al comercio entre sus miembros, generalmente acordadas por medio de negociaciones bilaterales.

La diferencia de China respecto a otros países de economía centralmente planificada o en transición a un sistema mixto, y a la mayoría de los que componen la omc, es el gran peso específico de su economía, ya señalado, que puede provocar un grave daño a otras con las que comercie, aun en la situación óptima en la que sus autoridades cumplan con las reglas básicas y no impongan restricciones no permitidas a su comercio exterior ni recurran a medidas tipificadas como de competencia desleal.

Por su parte, China ha tenido que otorgar concesiones que quedaron estipuladas en sus convenios bilaterales con países como Estados Unidos, Canadá y, curiosamente, con México, - por nombrar los tres firmantes del Tratado de Libre Comercio de América del Norte-, y con regiones como la Unión Europea, que en la mayoría de los casos se harán extensivas a los demás miembros de la omc.

\section{Obligaciones de las economías que ingresan a la ОМС}

Antes de analizar el caso de la República Popular China en lo referente a su preparación para ingresar a la OMC y a las condiciones específicas que se le impusieron para finalmente aceptarla como integrante, conviene referirse a las obligaciones de todo país miembro de la organización, que se derivan del GatT (wTo, Accessions Gateway, Principles of the Trading System): 
1) El principio básico sobre el que se sostenía el GATT está asentado en la Cláusula de nación más favorecida, consistente en la obligación de todos los pertenecientes al mismo y ahora de la OMC, de otorgar iguales ventajas arancelarias y no arancelarias, que se hubieran acordado bilateral o multilateralmente con un país determinado o grupo de éstos, al resto de los miembros, lo que garantiza la reciprocidad entre todos los integrantes de la OMC.

Como excepciones al principio de reciprocidad conjunta están las reducciones negociadas dentro de un proceso de integración formal, por ejemplo, una zona de libre comercio, una unión aduanera o un mercado común; así como las concesiones preferenciales que las naciones avanzadas otorguen a los países en desarrollo, y que éstos no quedan obligadas a reciprocar.

2) No imponer restricciones cuantitativas a las importaciones que no hayan sido acordadas de manera específica y con carácter temporal.

3) No imponer impuestos internos más altos a los productos importados que a los de producción nacional (el llamado tratamiento nacional).

4) Limitar la imposición de tarifas y otras cargas que se añadan a las tarifas de importación, excepto las normales que constituyan la contrapartida por servicios prestados.

5) Más específicamente para economías centralizadas o mixtas con un fuerte ingrediente estatal está la limitación en cuanto a las cargas que puedan imponer las corporaciones estatales de comercio exterior; con esta regla se espera reducir los efectos costoprecio de la competencia monopolística.

De ahí la exigencia de que se transparenten, con información a detalle, las actividades comerciales -importaciones y exportaciones - efectuadas por las corporaciones gubernamentales de los países de economía fuertemente controlada por el Estado, con inclusión de costos y otros elementos que contribuyan a la formación de los precios base, sobre todo para los productos de exportación, además de las fuentes de financiamiento, los términos y plazos de contratación, y los tiempos de entrega.

La transparencia es indispensable para evitar prácticas tales como la imposición de cargas no especificadas a los productos importados que los coloquen en desventaja frente a la producción nacional; discriminación de los productos distinta de las cargas internas ya señaladas o de unos proveedores extranjeros con relación a otros. En cuanto a las exportaciones, se trata de limitar la práctica de dumping.

Hasta la fecha, el problema es que situaciones como las mencionadas aquí son difíciles de determinar, lo que en ocasiones lleva a las economías que se sienten afectadas por cualquier tipo de discriminación a entablar una disputa. Sólo entonces se hacen patentes ese tipo de prácticas desleales al comercio multilateral. 


\section{Cambios institucionales y liberalización de aranceles en China}

Más que en lo relativo a la reducción de tarifas arancelarias, que se mencionará brevemente, iniciada de manera unilateral por China desde antes de su ingreso a la omc, aquí el énfasis recae en los aspectos institucionales. Lo anterior quiere decir descentralización administrativa de su aparato público a cargo del comercio exterior, pero sobre todo, descentralización económica, entendida ésta como la extensión del privilegio de comerciar directamente con el exterior, a una diversidad de actores económicos que antes tenían que recurrir al Estado para que en su beneficio efectuara los intercambios comerciales de este tipo.

En lo referente a tarifas arancelarias, tema recurrente a nivel internacional desde que nació el GATT en 1947 (Keesing's, 1995:40386), podría señalarse que en la República Popular China, al momento de su ingreso a la omc, eran todavía altas, por lo que su reducción continuará siendo elemento esencial del proceso de liberalización comercial de esa nación; ${ }^{4} \mathrm{y}$, sin embargo, la influencia de los aranceles en la determinación de los flujos de comercio es relativamente menor en ese país que en las economías de mercado, debido a que, en la práctica, se recauda una proporción extremadamente baja de las tarifas nominales: alrededor de 20\% en promedio en el año de 1999 (Yamazawa e Imai, 2001:91).

En China, una proporción significativa de las importaciones de materias primas y bienes intermedios entra bajo la provisión de procesamiento para la exportación, y queda exenta de impuestos a su ingreso al país; lo mismo sucede con la maquinaria y el equipo especializado para uso en proyectos estatales, o los de participación extranjera y los totalmente extranjeros respaldados por el gobierno. Simplemente como referencia, en 1998, las importaciones libres de impuestos representaron $48.9 \%$ de las totales, y $44.4 \%$ en 1999. En ese mismo año, $57 \%$ de las exportaciones fueron producidas sobre la base de importaciones de insumos bajo la provisión ya señalada (Yamazawa e Imai, 2001:91).

Pero tanto, en lo relativo a tarifas arancelarias como a restricciones no arancelarias, el temor tan grande de la comunidad internacional al ingreso de la República Popular China a la OMC se deriva de la creencia de que su sistema tradicional de comercio exterior sigue vigente, y que su ingreso a esa organización se traducirá en un crecimiento espectacular de su participación en el comercio mundial, sin cambio apreciable en sus prácticas comerciales.

No hay que olvidar que China ya se había insertado en las corrientes mundiales de comercio antes de su entrada a la OMC, de manera tal que, en el futuro próximo, es de esperarse una exposición creciente de su economía a la incursión comercial de otros países, expresada como incremento y diversificación de sus importaciones, o a la inversión ex-

4 En 2002, el primer año de su participación como miembro pleno en la OMC, China redujo los aranceles de más de 5300 productos y quedó con una tasa general promedio de 12\% (Agrawal y Sahoo, 2003:2545). 
tranjera directa (IED), desde luego en monto, ${ }^{5}$ pero también en cuanto a la variedad de países en los que se origina, y de las ramas industriales o de servicios a las que se destina.

\section{Evolución del papel del Estado en el manejo del comercio exterior en China}

En realidad, hace ya tiempo que China cumple con la condición esencial requerida para el ingreso de una economía a la OMC, que su comercio exterior no esté totalmente bajo el control de un monopolio. Eso, desde el momento en que comenzó a permitirse a entidades gubernamentales distintas del gobierno central —al inicio de los ochenta-, que comerciaran directamente con el exterior, y más claramente en los noventa, cuando se otorgaron permisos a la importación de insumos para la producción interna, y en algunos casos de productos terminados, a empresas estatales y colectivas, así como a otras con participación de capital privado, chino y extranjero.

Aún así, en algunas áreas estratégicas, el Estado sigue reteniendo el control total - $\mathrm{O}$ casi- de las operaciones con el exterior, básicamente de las importaciones, y en cada oportunidad la corporación o corporaciones a cargo de la comercialización de los bienes actúa como monopolio, o en el mejor de los casos, se trata de competencia monopolística. Este control se acentúa en el sector agropecuario para algunos productos básicos (granos, aceite vegetal, azúcar, tabaco y algodón), pero también están el petróleo crudo y el procesado y los fertilizantes químicos, entre otros productos industriales (Williams, 2000:19-20).

A ese respecto, es importante señalar que esta situación anómala, para los fines de un proceso generalizado de liberalización comercial, tendrá que modificarse cuando se haya cumplido el periodo de transición otorgado a la República Popular al momento de su ingreso a la OMC; más todavía, hay indicios de que las autoridades de ese país tratarán de adelantarse a los acontecimientos, como lo demuestran las políticas de liberalización parcial del comercio interno de cereales en China. ${ }^{6}$

Brett Williams (Williams, 2000:3-4) examina con detalle algunos cambios introducidos a lo largo de los años ochenta y noventa en el sistema estatal de comercio exterior que prevalecía en China hasta 1978, antes de que se introdujeran las reformas a la economía. $\mathrm{Al}$ analizarlos pone énfasis en las modificaciones a los mecanismos de control de las importaciones de varios tipos, lo que quiere decir variaciones en el grado de participación de las corporaciones estatales en su manejo.

5 De acuer do con estimaciones de la Conferencia de las Naciones Unidas para Comercio y Desarrollo (UNCTAD, por sus siglas en inglés), el flujo bruto de IED a China en 2002 por primera vez superó los 50000 millones de dólares estadounidenses - 52700 ingresar on y 2850 salieron - (UNCTAD, 2003), con lo cual este país pasó a ser el receptor más importante bruto y neto de esos recursos.

6 Aparentemente, en 2002 se eliminó el requisito de permisos de importación y desaparecieron las cuotas a productos clave como son granos, algodón, lana y fertilizantes químicos (Agrawal y Sahoo, 2003:2545). 
Prácticamente desde los cincuenta hasta 1978, en China existía una diversidad de corporaciones especializadas estatales de comercio exterior (CEECE), cada una de las cuales constituía un monopolio en su rama, aunque limitado en sus actividades por los planes quinquenales de ese país; como conjunto, dichas corporaciones dependían directamente del Ministerio de Comercio y Relaciones Económicas con el Exterior.

Es a principios de los ochenta que, junto con las reformas a la estructura de la economía interna y la gradual apertura al exterior, todavía circunscrita a unas cuantas Zonas Económicas Especiales en las costas Este y Sur de China, otros ministerios comenzaron a establecer sus propias CEECE, con las que intervenían directamente en las actividades comerciales con el exterior, básicamente para obtener los insumos requeridos por las empresas estatales bajo su control.

También como parte de la liberalización administrativa de este tipo de comercio, cobraron importancia las corporaciones especializadas provinciales de comercio exterior (CEPCE), cuya operación quedaba restringida al territorio de la provincia en cuestión; de cualquier manera, para el año de 1990, 443 de las 500 corporaciones estatales de comercio exterior existentes entonces en China, eran provinciales (Williams, 2000:3).

Esa modalidad surgió a partir de una iniciativa presentada por los gobiernos de las provincias sureñas de Guangdong y de Fujian a fines de los setenta, en cuanto a que se les otorgara autonomía respecto al gobierno central en lo concerniente a sus intercambios comerciales y económicos con el exterior, que lograron en julio de 1979 (González y Gómez, 1999:94). En dicha práctica les seguirían otras provincias costeras, y en la actualidad, esa norma se aplica a provincias y gobiernos locales de todo el país, con excepciones y limitaciones que en general siguen privilegiando a las provincias costeras.

\section{El derecho a operar en comercio exterior}

Las empresas estatales productoras de bienes fueron las primeras entidades que se beneficiaron con el derecho a operar en comercio exterior, lo que en un principio era simplemente un permiso para importar materias primas y bienes intermedios no disponibles en el mercado interno; más adelante, esa prerrogativa incluiría la posibilidad de importar bienes terminados similares a los producidos por las mismas, a condición de que las empresas solicitantes contribuyeran con exportaciones a la obtención de divisas.

Como ejemplo del desarrollo tan rápido de este mecanismo de liberalización del comercio exterior, para 1995, cinco mil grandes empresas ya gozaban, en forma limitada o amplia, de este privilegio en todo el país (Williams, 2000:3).

Muy pronto, el sistema se ampliaría para incluir, además de las empresas estatales ya mencionadas, a las de participación extranjera - las estatales, o las colectivas dependientes de los gobiernos locales, en las que parte del capital es extranjero- y a las totalmente extranjeras. Éstas, desde un principio pudieron importar materias primas y bienes inter- 
medios necesarios para su producción, primero como un privilegio, y posteriormente amparadas por leyes y reglamentos de aplicación general que fueron emitiéndose a lo largo de los años noventa.

Los proyectos llave en mano comprendían la importación de la maquinaria requerida para su operación, porque, además del financiamiento externo que representaban, con ellos se perseguía la obtención y, de ser posible, la absorción de nuevas tecnologías, generalmente integradas en la maquinaria y el equipo.

Por último, apenas en 1999, después de haberse legitimado la propiedad privada de los medios de producción en la Constitución de la República Popular China, ${ }^{7}$ comenzaría a otorgarse el derecho a operar en comercio exterior a empresas privadas chinas, todavía de manera restringida.

Antes de eso, en 1992, ese derecho se haría extensivo a algunas corporaciones especializadas estatales de comercio interior (CEECI), de las cuales, para 1995, existían 62 que combinaban ambas actividades comerciales (Williams, 2000:4). También a fines de 1992, algunas corporaciones sino-extranjeras comenzarían a participar de manera amplia en comercio exterior, a través de sus comercializadoras.

\section{Condiciones impuestas a China para su ingreso en la OMC}

El punto de partida en el caso de China es el relativo a la forma como las CEECE deberán conducirse en el intercambio con el exterior, en un proceso para liberalizar y descentralizar gradualmente, a lo largo de un periodo de cambio, cuya duración quedó fijada en el convenio de ingreso.

Cabe hacer notar que casi todas las condiciones específicas impuestas a la República Popular, distintas de las ya señaladas para cualquier economía que entre a la OMC, surgieron en las negociaciones bilaterales con determinados países miembros de la organización; la más definitoria de todas fue la efectuada con Estados Unidos.

Porque entre los requisitos que hubo de cumplir China antes de ingresar a la OMC, estuvo buscar la aprobación de cada uno de los países miembros de ese organismo, lo que hizo a través de negociaciones paralelas llevadas a cabo a lo largo de poco más de quince años, en las que sus contrapartes se centraron en los aspectos que les permitieran aprovechar sus ventajas comparativas frente a esa nación, o como lo hizo el gobierno de México, que impuso tasas muy altas a alrededor de 1300 tarifas arancelarias, ${ }^{8}$ como compensación frente a lo que considera prácticas desleales de comercio por parte de China.

7 Cuando se revaloró a las empresas privadas y a las no-estatales, al incluirlas como "componentes importantes de la economía social ista de mercado", y se reconocieron múltiples formas de propiedad, entre ellas la propiedad privada de los medios de producción (Keesing's, 1999: 42783 y 42841).

8 Por ejemplo en prendas de vestir, hilados y tejidos de fibras sintéticas y artificiales, y sustancias químicas orgánicas (Secretaría de Economía, 2002:9). 
En todo caso, de las muchas negociaciones bilaterales que tuvo que emprender la República Popular China, los términos de las llevadas a cabo con Estados Unidos en 1999 ([The] White House Office of Public Liason, 1999) y con la Unión Europea en 2000 (EU in the World, 2000) fueron la base de las condiciones finalmente asentadas en el protocolo redactado con la OMC para su ingreso a dicha organización.

\section{Puntos más importantes de la negociación sino-estadounidense}

La República Popular China luchó por muchos años hasta obtener la aprobación de Estados Unidos para su ingreso a la omc, lo que logró en 1999, y este hecho es considerado por la mayoría de los integrantes de ésta como la superación del obstáculo fundamental para su aceptación. A ese asentimiento le seguiría, entre otras, la de la Unión Europea en el año 2000 y la de México, apenas en septiembre de 2001.

Como puntos por destacar de la negociación de China con Estados Unidos están, en primer lugar, la inclusión de la totalidad de los productos agrícolas e industriales y de los servicios de todo tipo en el esfuerzo de liberalización comercial del primero, así como la reducción de tarifas arancelarias al conjunto de productos industriales, de un promedio de 24.6\% que se tenía en 1997, a 9.4\%, aplicable a partir de 2005 ([The] White House Office of Public Liason, 1999:1-2).

En áreas prioritarias para Estados Unidos se acordó, por ejemplo, que los impuestos a la importación de algunos productos que forman parte de la tecnología de la información, como computadoras, semiconductores, y equipo para Internet, bajaran de $13.3 \%$ promedio al momento de la negociación, a $0 \%$ para 2005, y que se redujeran las tarifas arancelarias aplicadas por China a algunos productos agrícolas prioritarios de Estados Unidos (entre otros carne de res, puerco y pollo, uvas, vino y queso), de $31.5 \%$ promedio prevaleciente antes de la negociación a 13.3\%, aplicable como límite en enero de 2004.

En lo referente al levantamiento de restricciones no arancelarias por parte de China, Estados Unidos obtuvo el compromiso de las autoridades de ese país, primero, en cuanto a expandir el acceso de productos estadounidenses con contenido de maíz, trigo, arroz, cebada, soya y algodón, y a permitir, todavía con restricciones, el comercio privado de productos agrícolas; a eliminar totalmente los subsidios a la exportación de algunos productos agrícolas, por ejemplo maíz, arroz y algodón; ${ }^{9}$ a descentralizar completamente el comercio de los productos industriales, tanto importaciones como exportaciones, y a am-

9 En materia de agricultura ha habido retrocesos, por ejemplo, la introducción de reglamentaciones sanitarias antes no existentes, o el requisito de obtener un certificado sin que se especifiquela forma de obtención del mismo- para la importación de cereales genéticamente modificados-. Quizá más importante es que sigue subsidiándose la exportación de maíz de China, entre $\$ 30.00$ y $\$ 40.00$ dólares por tonelada (FEER, 5 de diciembre de 2002:32-33). 
pliar el acceso al mercado chino a los proveedores externos de servicios, específicamente en las áreas de telecomunicaciones, banca, valores, seguros y servicios profesionales (legales, de contabilidad, de ingeniería y arquitectura).

Dada la proclividad de las relaciones comerciales sino-estadounidenses a entrar en conflicto, aspectos cruciales de su negociación fueron los relativos a solucionar controversias que llevaban mucho tiempo pendientes, y el dejar abierta la posibilidad, para Estados Unidos, de imponer sanciones a China en caso de incurrir ésta en prácticas desleales de comercio, o de limitar el crecimiento de las importaciones de productos chinos, que resultara en daño al mercado estadounidense, por ejemplo:

a) se estableció un mecanismo de salvaguarda, efectivo por doce años a partir del ingreso de China a la oMc, por el que Estados Unidos puede limitar el incremento de las importaciones de algunos productos chinos, si considera que causa daño a su mercado;

b) se mantuvo la metodología de considerar a China economía no de mercado, por quince años, como recurso antidumping para las importaciones provenientes de ese país;

c) se le exigió la liberalización gradual de los servicios de Internet y de las telecomunicaciones vía satélite, situación que, en cuanto suceda, se traducirá en un mayor acceso de las compañías extranjeras al aprovisionamiento de esos servicios;

d) A partir de su ingreso a la OMC China se comprometió a permitir que compañías extranjeras recurrieran al autofinanciamiento en su mercado. Ese compromiso se añade a los ya establecidos por los que se liberaliza la importación, distribución, venta y servicios de mantenimiento de automóviles, ${ }^{10}$ y a la reducción acelerada de las tarifas de importación de automóviles, de $80-100 \%$ que se tenía en 2000 , a $25 \%$, pero a lo largo de un periodo que se extenderá hasta julio de 2006;

e) en materia de telecomunicaciones y seguros, Estados Unidos accedió a limitar su participación en la propiedad de las empresas en coinversión a un máximo de 50\%, y a cambio de eso, China se comprometió a eliminar las restricciones geográficas existentes hasta entonces en esas ramas. ${ }^{11}$

\section{Efectos iniciales sobre la relación comercial entre Estados Unidos y China}

Ante todo, cabe señalar que el tema de los efectos iniciales de la entrada de China a la OMC sobre la relación comercial y económica entre esa nación y Estados Unidos se aborda aquí

10 No obstante, en los primeros siete meses del año 2002, el primero después de su ingreso a la OM C, el 11 de diciembre de 2001, China ni remotamente se había acercado a la cuota de importación fijada para automóviles, con un valor de $\$ 7900$ millones de dólares, y a fines de julio solamente había importado autos por un total de $\$ 1600$ millones de dólares, aproximadamente $20 \%$ de lo esperado, ello a pesar dequela demanda interna por esos productos seha disparado (FEER, 5 dediciembre de 2002:32).

11 Este punto forma parte de una lista de reformas que deben comenzar a aplicarse a fines de 2003 (FEER, 2 de octubre de 2003:28). 
porque tiene una importancia primordial para México, particularmente los cambios que pudieran presentarse en cuanto al comercio.

Como ejemplo de esa relevancia se tiene que, entre 1993 y el año 2002, las importaciones estadounidenses originarias de México crecieron a una tasa de $7.1 \%$ y las de China a $8.8 \%$ — promedio anual—, en ambos casos, básicamente a costa de una reducción en las importaciones estadounidenses originadas en Japón, Corea y Taiwan, las cuales decrecieron en números absolutos para el mismo periodo (véase Cuadro 1).

El ingreso de China a la OMC se traducirá en efectos directos sobre el comercio bilateral China-Estados Unidos y sobre los niveles y ramas de inversión extranjera directa, en este caso de Estados Unidos en China, y en efectos indirectos tales como fricciones de todo tipo en su relación comercial mutua, seguidas, quizá, por ajustes que en última instancia podrían llevar al mejoramiento de la misma.

En cuanto a la naturaleza de la relación comercial sino-estadounidense, está basada en sus respectivas ventajas comparativas, según las cuales China aporta trabajo a la relación, a través de la exportación de manufacturas intensivas en mano de obra. En tanto, Estados Unidos contribuye con capital y tecnología, ambos integrados en sus proyectos de inversión en China, principalmente en el sector servicios y tierra, por medio de la exportación de productos agropecuarios.

Siguiendo esa pauta y tomando en cuenta el déficit tan alto de Estados Unidos respecto a China, al momento de su ingreso a la OMC, ${ }^{12}$ es de esperar un incremento del mismo en los años subsiguientes a su entrada, que podría reducirse en el plazo más largo, en la medida que Estados Unidos entre al mercado chino de servicios profesionales y de otro tipo, e incremente su participación en la industria manufacturera, de preferencia para consumo interno.

Por lo pronto, a partir de su ingreso en la oMc, el aprovechamiento más amplio de las ventajas comparativas de China en manufacturas intensivas en mano de obra, afectará particularmente la industria textil estadounidense, en donde se prevé una pérdida de cerca de 155000 empleos, después de que caduque en 2005 el Acuerdo Multifibras actualmente vigente, por el que Estados Unidos impone restricciones cuantitativas a la importación de productos textiles de origen chino.

La impresión prevaleciente en 2002, confirmada en 2003 al superar China a México como fuente de abastecimiento de importaciones a Estados Unidos ${ }^{13}$ era que, en el futuro

12 De 28100 millones de dólares en 2001, de un monto total de comercio de $\$ 80,500$ millones de dólares (EIU, febrero, 2002:35). Posteriormente, de enero a marzo, inclusive, de 2003, China exportó 17658 millones de dólares a Estados Unidos e importó 7933 de este país, con un superávit de 9 725, de un comercio total de 25591 millones de dólares (EIU, junio 2003:41).

13 De enero a agosto de 2003 las importaciones de Estados Unidos procedentes de China fueron de 93820 millones de dólares, un incremento de $21.47 \%$ respecto al mismo periodo en 2002 , y las de M éxico de 90 167, un crecimiento porcentual de apenas 1.3\% respecto a los mismos meses en 2002 (United States International Trade Commission, 2003). 


\section{Cuadro 1 \\ Importaciones de Estados Unidos \\ originarias de México y de algunas economías de Asia \\ (millones de dólares estadounidenses)}

\begin{tabular}{|c|c|c|c|c|}
\hline & De México & De China & De Japón & $\begin{array}{c}\text { De Taiwan } \\
\text { y Corea del Sur }\end{array}$ \\
\hline 1993 & 68000 & 54000 & 184000 & 72000 \\
\hline 1994 & 74000 & 58000 & 179000 & 69000 \\
\hline 1995 & 83000 & 61000 & 166000 & 71000 \\
\hline 1996 & 92000 & 65000 & 145000 & 65000 \\
\hline 1997 & 98000 & 71000 & 139000 & 63000 \\
\hline 1998 & 94709 & 71156 & 121982 & 57059 \\
\hline 1999 & 109707 & 81786 & 131404 & 66461 \\
\hline 2000 & 135911 & 100063 & 146577 & 80815 \\
\hline 2001 & 131433 & 102281 & 126602 & 68576 \\
\hline $2002 p$ & 134732 & 125168 & 121494 & 67775 \\
\hline T.M.A. de crec. (\%) & (7.1) & $(8.8)$ & $(-4.1)$ & $(-0.6)$ \\
\hline
\end{tabular}

Fuentes: Secretaría de Economía, con datos del Departamento de Comercio de Estados Unidos, México, 2002, presentación en Power Point, para 1993-1997, p. 21, y United States International Trade Commission, E.U., para 1998-2002.

$\mathrm{p}$ Datos preliminares.

próximo, nuestro país será uno de los más afectados debido a la mayor participación de China en el mercado estadounidense. O sea, que no todos los avances de la República Popular en la captura de dicho mercado se traducirán en un incremento del déficit total de Estados Unidos respecto al resto del mundo, sino parte de éstos corresponderán a una pérdida de áreas de competencia de naciones como México.

Por el contrario, para los países avanzados, el ingreso de China a la OMC representa una expansión de sus oportunidades de participación en ramas de la economía de este país hasta ahora reguladas.

A ese respecto, Estados Unidos puede ser una de las naciones que en el mediano plazo se beneficie más de la apertura china, porque tiene ventajas comparativas significativas en el aprovisionamiento de servicios con un alto contenido de tecnología, principalmente en mercadotecnia y en servicios altamente especializados, como los financieros.

No sólo eso, sino que el comercio podría ampliarse y las inversiones ir a sectores económicos hasta ahora no previstos, si la apertura conduce a la creación de nuevas necesidades en China que no puedan ser satisfechas localmente.

En contra de esa posibilidad actúa la inconsistencia de las reglamentaciones en China, que lleva a las empresas extranjeras en operación en ese país, a confusión sobre la forma adecuada en que deben ajustarse a ellas, y desconfianza en cuanto a si verdaderamente se respetarán los derechos a la propiedad intelectual. 


\section{Negociaciones entre China y la Unión Europea}

Por otra parte, la negociación de China con la Unión Europea, concluida en mayo de 2000, también es relevante, porque en ella, la República Popular hizo concesiones adicionales a las otorgadas a Estados Unidos, por ejemplo, la promesa de reducir gradualmente el monopolio existente hasta ahora para la importación de petróleo crudo y procesado, y de ciertos tipos de fertilizantes, así como para la exportación de seda; una mayor flexibilidad en cuanto al tipo de automóviles que se permita producir a las empresas extranjeras en China, y un acuerdo sanitario y fitosanitario, que facilitará la solución de controversias pendientes.

Pero más que enumerar cada uno de los puntos en los que ambas negociaciones (la de 1999 con Estados Unidos y la de 2000 con la Unión Europea) se diferencian, basta decir que la relación comercial entre ésta última y China también está basada en sus respectivas ventajas comparativas, de acuerdo con las cuales la República Popular aporta trabajo, y los países del bloque europeo aportan capital, tecnología y tierra, con superávit comercial para China en 2001: 40800 millones de dólares, de un comercio total de 93800 millones $^{14}$ ([Grupo del] Banco Mundial, estadísticas comerciales de la Unión Europea con regiones y países) que podrá ser compensado en la medida que se haga efectiva la liberalización de los servicios en este país, y la de la agricultura, para dar entrada a algunos productos de ésta, y a otros manufacturados, pero de origen agropecuario.

Simplemente como referencia, para 2001, el año en el que se cuenta con esta información, las importaciones de la Unión Europea procedentes de México fueron mínimas (6.4) en comparación con las originadas en China (67.3), Japón (67.2) y la suma de las procedentes de Taiwan y de la República de Corea (40.4), todas calculadas en miles de millones de dólares estadounidenses ${ }^{15}$ (WTO, 2003: estadísticas sobre comercio).

\section{Preocupación en México por el ímpetu comercial reciente de China}

En lo referente a México, con el fin de entender y tratar de explicar el temor tan grande de autoridades y grupos empresariales de nuestro país al ímpetu comercial actual de China, habría que señalar algunas características de la economía de ésta que acrecientan sus posibilidades de acción en los mercados internacionales de bienes y servicios, y reflexionar sobre las posibilidades reales de que estas ventajas se acentúen en el mediano plazo.

14 Cubre solamente cinco de los quince países de la Unión Europea, pero representan más de $90 \%$ del intercambio comercial de este grupo con China. Esos países son Alemania, Francia, Gran Bretaña, Italia y los Países Bajos.

15 Las mismas que se compararon en el cuadro sobre importaciones de Estados Unidos originarias de M éxico y de algunas economías de Asia. 
Según estimaciones del FMI, basadas en la evaluación del PIB a la paridad del poder adquisitivo de las monedas locales de los diferentes países, la economía china es, en la actualidad, la segunda más grande del mundo (véase el Cuadro 2). Este método de evaluación exagera su importancia relativa, pues la coloca muy por encima de la japonesa o la alemana, pero aún a precios constantes, al tipo de cambio corriente entre la moneda local (renminbi) y el dólar estadounidense, el PIB de China se sitúa entre el sexto y séptimo lugares más significativos del mundo.

Como quiera que sea, la economía china es tan importante y su inserción en las corrientes mundiales de comercio se ha producido en tan pocos años, en realidad durante la última década del siglo xx, de manera tal que sus socios comerciales, grandes y pequeños, no han podido todavía evaluar su capacidad, para incursionar primero y avanzar después, en un creciente número de ramas industriales. Por lo pronto, en 2002 China contribuyó con $4.7 \%$ de las exportaciones mundiales de bienes y servicios (véase el Cuadro 2).

A pesar de más de veinte años de aplicación de reformas a su estructura económica y de su gradual apertura al exterior a todo lo largo del mismo periodo, en China todavía hay un alto grado de intervención del Estado en la economía, sobre todo en comercio exterior, que se manifiesta como acción coordinada entre las corporaciones especializadas estatales en ese ramo dependientes de algunos ministerios y el gobierno.

Aunque la mayoría de las mercancías ya no está sujeta al control monopólico por parte del Estado, se da el caso de bienes cuya transacción depende totalmente del gobierno, a través de las corporaciones especializadas estatales de comercio exterior. Cuando eso sucede, el producto o grupo de productos es manejado por una corporación específica, o un número reducido de ellas, por ejemplo:

- China National Cereals, Oil \& Foodstuff Import and Export Co. se hace cargo de la comercialización internacional de los cereales en China, pero además participa en la del aceite vegetal y del azúcar.

- China National Tobacco Import \& Export Co. maneja el tabaco.

- China National Chemical Import \& Export Co. trata la importación y distribución interna de los fertilizantes químicos, y

- China National Textiles Import \& Export Co. está encargada del comercio externo de textiles.

Específicamente en lo concerniente a México, además del avance de China en el mercado estadounidense (véase Cuadro 1), en el cuales ambos países compiten, ${ }^{16}$ es preocupante la tendencia del comercio exterior mexicano al déficit creciente — en la medida que

16 En 2001, China cubría 13.1\%, 12.2\%, y 11.5\%, respectivamente, de las importaciones estadounidenses de textiles, electrónicos y confección, en tanto M éxico participaba con $9.2 \%, 15.9 \%$ y $13.4 \%$ de las importaciones de Estados Unidos para los mismos productos. Sin contar con que China cubría 


\section{Cuadro 2}

Participación de regiones, grupos y países en el PIB, las exportaciones de bienes y servicios y la población mundiales, 2002

\begin{tabular}{lccr}
\hline & PIB & $\begin{array}{c}\text { Exportaciones de bienes } \\
\text { y servicios }\end{array}$ & Población \\
\hline Mundial & & $100.0^{\mathrm{b}}$ & $100.0^{\mathrm{c}}$ \\
Países desarrollados (29) & $100.0^{\mathrm{a}}$ & 74.6 & 15.4 \\
Los más desarrollados (7) & 55.7 & 45.3 & 11.5 \\
Estados Unidos & 44.0 & 12.4 & 4.7 \\
Japón & 21.1 & 5.9 & 2.1 \\
Alemania & 7.1 & 9.1 & 1.3 \\
Países en desarrollo (125) & 4.4 & 20.5 & 78.1 \\
Asia (25) & 38.1 & 10.0 & 52.4 \\
China & 22.9 & 4.7 & 20.8 \\
América Latina y Caribe (33) & 12.7 & 4.5 & 8.3 \\
\hline
\end{tabular}

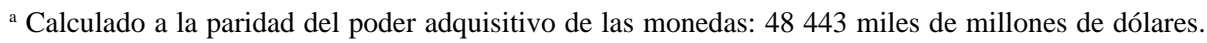

${ }^{\text {b }}$ A precios corrientes: 7838 miles de millones de dólares.

c 6234 millones de personas (World Almanac Books, 2003:857).

Fuente: Elaborado con datos del FMI, World Economic Outlook, April 2003, pp. 161-167, 171 y 200.

se ha perdido la ventaja de la devaluación de diciembre de 1994-, que responde a causas estructurales de nuestra economía a las que la República Popular es totalmente ajena. Nuestro déficit frente a China, también creciente, aunque mínimo en comparación con el total del comercio mexicano, refleja el nulo avance de los productos mexicanos en el mercado chino.

Los cuadros 3 y 4 sirven como base de comparación entre el comercio de China y el de México. En éstos se observa el rápido crecimiento del comercio total de cada uno de los dos países para los años de 1994 a 2002 y las diferencias en el comportamiento de sus respectivos balances comerciales para los años considerados, de superávit creciente en el caso de China, y de déficit creciente para México.

El Cuadro 5 muestra el estado de la relación comercial entre los dos países, aunque poco significativa como proporción de sus respectivos totales, refleja un aprovechamiento mínimo de la creciente apertura de la economía china por parte de México.

\section{Implicaciones para México del ingreso de China a la oMC}

La negociación entre China y México para el ingreso de este último país a la omc concluyó apenas el 13 de septiembre de 2001 "un día hábil antes de que el Protocolo (de adhesión de China a la OMC) fuera aprobado por el pleno del grupo de trabajo", como hiciera notar quien entonces era un alto negociador del gobierno mexicano (De la Calle, 2002:157).

$62.3 \%$ y $60.2 \%$, respectivamente, de las importaciones estadounidenses de calzado y de juguetes, rubros en los que M éxico tiene mínima participación (Secretaría de Economía, 2002:24). 
Cuadro 3

China, comercio exterior

(miles de millones de dólares estadounidenses)

\begin{tabular}{lcccc}
\hline Años & Total & Exportaciones & Importaciones & Balanza comercial \\
\hline 1994 & 236.6 & 121.0 & 115.6 & 5.4 \\
1995 & 280.9 & 148.8 & 132.1 & 16.7 \\
1996 & 289.9 & 151.1 & 138.8 & 12.2 \\
1997 & 325.2 & 182.8 & 142.4 & 40.4 \\
1998 & 323.9 & 183.7 & 140.2 & 43.5 \\
1999 & 360.6 & 194.9 & 165.7 & 29.2 \\
2000 & 474.3 & 249.2 & 225.1 & 24.1 \\
2001 & 509.8 & 266.2 & 243.6 & 22.6 \\
2002p & 607.2 & 325.7 & 281.5 & 44.2 \\
T.M.A. de crec. \% & $(11.0)$ & $(11.6)$ & $(10.4)$ & \\
\hline
\end{tabular}

Fuentes: National Bureau of Statistics, China Statistical Yearbook 2001, p. 586, para 1994-1996; The Economist Intelligence Unit (EIU), Country Profile 2003, China, UK, 2003, pp. 66-7, 1997-2001, y EIU, Country Report, June 2003, China, UK, 2003, p. 5, para 2002.

p Datos preliminares.

Cuadro 4

México, Comercio exterior (miles de millones de dólares estadounidenses)

\begin{tabular}{lcccc}
\hline Años & Total & Exportaciones & Importaciones & Balanza comercial \\
\hline 1994 & 140.3 & 60.9 & 79.4 & -18.5 \\
1995 & 151.9 & 79.5 & 72.4 & 7.1 \\
1996 & 185.5 & 96.0 & 89.5 & 6.5 \\
1997 & 220.2 & 110.4 & 109.8 & 0.6 \\
1998 & 242.9 & 117.5 & 125.4 & -7.9 \\
1999 & 278.4 & 136.4 & 142.0 & -5.6 \\
2000 & 341.0 & 166.5 & 174.5 & -8.0 \\
2001 & 326.7 & 158.5 & 168.2 & -9.7 \\
$2002 p$ & 329.5 & 160.8 & 168.7 & -7.9 \\
T.M.A.de crec. \% & $(10.0)$ & $(11.4)$ & $(8.7)$ & \\
\hline
\end{tabular}

Fuentes: Nacional Financiera, Revista El Mercado de Valores, varios números; Organización Mundial de Comercio, Informe Anual 2001, e INEGI, Resumen de la Balanza de Pagos, en www.inegi.gob.mx, información estadística, para 2002.

$\mathrm{p}$ Datos preliminares.

De los 37 integrantes de la OMC que solicitaron entablar negociaciones bilaterales con China relativas a su ingreso al organismo, México fue el último país en otorgar su autorización, ${ }^{17}$ quizá porque la magnitud tan grande de la economía china obligó a diferentes gobiernos de este país a analizar con sumo cuidado las implicaciones que tendría

17 Desde el inicio de la vigencia del GATT, cualquier negociación comercial o relativa al ingreso de nuevos socios al acuerdo pasaba por dos procesos paralelos: un acuerdo multilateral y acuerdos bilaterales múltiples que emprendían las partes contratantes - hoy conocidas simplemente como integrantes de la OM C- a solicitud de ellas, o por su relevancia en la toma de decisiones. 


\section{Cuadro 5}

Comercio exterior entre China y México, visto desde México (millones de dólares estodounidenses)

\begin{tabular}{ccccc}
\hline Años & Total & Exportaciones & Importaciones & Balanza comercial \\
\hline 1993 & 431.2 & 44.8 & 386.4 & -341.6 \\
1994 & 541.9 & 42.2 & 499.7 & -457.5 \\
1995 & 557.6 & 37.0 & 520.6 & -483.6 \\
1996 & 798.0 & 38.3 & 759.7 & -721.4 \\
1997 & 1293.3 & 45.9 & 1247.4 & -1201.5 \\
1998 & 1722.5 & 106.0 & 1616.5 & -1510.5 \\
1999 & 2047.4 & 126.3 & 1921.1 & -1794.8 \\
2000 & 3083.1 & 203.5 & 2879.6 & -2676.1 \\
2001 & 4309.0 & 281.8 & 4027.2 & -3745.4 \\
2002 & 6730.3 & 455.9 & 6274.4 & -5818.5 \\
$2003 *$ & 4956.0 & 300.5 & 4655.5 & -4355.0 \\
\hline
\end{tabular}

Fuentes: Secretaría de Economía, con datos de El Banco de México, México, 2002, para 1993-2001, y Grupo de trabajo: SHCP, Banco de México, Secretaría de Economía e INEGi, México, 2003, para 2002 y parcial 2003 en www.inegi.gob.mx

* Enero a julio, inclusive.

para nuestra economía tal hecho. Estas pueden ser resumidas en dos o — quizá- tres puntos principales, a saber:

1) A pesar de diferencias apreciables en los niveles de ingreso nacional bruto per cápita entre los dos países — 940 dólares estadounidenses a precios corrientes China y 5910 México para el año de 2002 ([Grupo del] Banco Mundial, 2003, reportes por países)—, hay coincidencias en el tipo de productos que exporta cada uno de ellos, básicamente manufacturas de industria ligera, en ambos casos con un alto contenido de trabajo.

A ese respecto, México enfrenta la posibilidad de continuar perdiendo participación en el mercado de Estados Unidos, principalmente en textiles, sobre todo porque en el convenio entre China y este último, concluido en 1999, se acordó dar por terminado en 2005 el Acuerdo Multifibras, por medio del cual Estados Unidos impone cuotas a la importación de textiles de varios tipos procedentes de China — lo que hasta ahora equivale a una ventaja comparativa para los textiles mexicanos-, pero también en productos como los electrónicos, por ejemplo.

2) A partir de la segunda mitad de los noventa, el mercado mexicano ha absorbido crecientes importaciones chinas, entre juguetes, calzado, ropa, herramientas menores y misceláneos.

3) México compite con China en la captación de inversiones extranjeras directas, con una clara ventaja para la última, en cuanto al volumen de capital privado extranjero que recibe anualmente. De acuerdo con estimaciones de la Conferencia de las Naciones Unidas para Comercio y Desarrollo (UNCTAD), en 2002 el flujo de inversión extranjera directa que llegó a China fue de 52700 millones de dólares de estodounidenses (UNCTAD, 
2003) muy superior al que ingresó a nuestro país en el mismo año, de 13897 millones de dólares estodounidenses (INEGI, 2003: Resumen de la Balanza de Pagos). Con el ingreso de China a la OMC podría acelerarse el ritmo de captación de ahorro externo por parte de este país, además de que su apertura financiera y bancaria, consecuente con su ingreso al organismo, seguramente atraerá a nuevos inversionistas.

\section{Conclusiones}

El ingreso de la República Popular China a la Organización Mundial de Comercio es consecuencia lógica del proceso de globalización observado en los últimos quince años. Éste comprende no sólo una creciente interdependencia económica de los diversos países del mundo, sino también el predominio de las economías de mercado sobre las distintas variantes de economías socialistas o de planificación centralizada, practicadas durante el siglo pasado.

En el caso de China comunista, desde principios de la década de los ochenta, sus dirigentes pusieron en marcha ambiciosas reformas que apuntan a tres grandes transformaciones estructurales: de una economía de propiedad estatal y colectiva a una mixta con predominio capitalista; de una economía y sociedad rurales a una urbana, y de una economía cerrada en lo comercial y financiero a una plenamente abierta.

Estos cambios han llevado a una convergencia del sistema chino con el capitalista, de tal manera que, independientemente de consideraciones institucionales, la mera funcionalidad de la economía internacional exigía el ingreso de China a la omc: una nación de esta magnitud no podía quedar fuera de las formalidades comerciales, como tampoco estaba al margen del Fondo Monetario Internacional y del Banco Mundial.

China emprendió una negociación para acceder a la OMC en 1986, nueve años antes de que ésta entrara en vigor, en un momento en que las condiciones económicas internacionales parecían ser propicias para la inserción plena, real e institucional, de este país a la economía mundial. Como ya se dijo, el órgano predecesor de la OMC —el GATT- no negaba el acceso a las economías socialistas, aunque establecía condiciones especiales a los candidatos por ingresar, cuyo control estatal sobre el comercio exterior fuera intenso y directo.

En contra de China estaba el que había sido parte del bloque encabezado por la URSS que, en su momento, rechazó ser parte de las organizaciones de Bretton Woods y las comerciales impulsadas por Estados Unidos y otros países capitalistas avanzados.

En todo caso, la asimilación de China comunista al GATT/OMC resultó mucho más complicada que las de otros países socialistas, por el tamaño de su economía y por su dinámica participación en las corrientes comerciales mundiales de bienes, servicios y capitales. De allí que, además del protocolo colectivo de adhesión, 37 partes contratantes del GATT pidieran entablar negociaciones bilaterales con la República Popular antes de su ingreso a la organización. 
En estas negociaciones, los miembros del GATT tenían como principal propósito obtener beneficios especiales del candidato a ingreso - sobre todo de uno como China, con fuertes mecanismos de control a su comercio exterior-. Por otra parte, no hay que olvidar que, en virtud de la cláusula de nación más favorecida, lo acordado bilateralmente entre dos miembros se transfiere automáticamente a los demás integrantes del organismo.

Como ya se mencionó, de las 37 negociaciones bilaterales, las más significativas para la República Popular y para el conjunto del GATT y, por ende, las más complicadas, fueron las realizadas con Estados Unidos y con la Unión Europea, que pactó en forma colectiva con China. Pero la negociación emprendida por México resultó la más controvertida, quizá por haber sido la última.

México prolongó hasta el límite posible su veto al ingreso de China a la OMC, probablemente con el fin de evitar que a última hora apareciera otra petición de negociación bilateral, con lo que se puso de manifiesto lo significativo que es para el futuro de los mercados mexicanos la creciente competencia de aquel país.

En dicha negociación, México logró que las controversias respecto a las cuotas de compensación contra las exportaciones chinas no puedan ser llevadas a un panel de solución antes del 2008; adicionalmente, nos beneficiamos de las condiciones pactadas por otros países miembros, por ejemplo la de seguir considerando a China como una economía no de mercado, durante 12 años para salvaguardas, y por 15 para casos nuevos de dumping (De la Calle, 2002:158).

Con o sin ingreso a la OMC, China ya constituye un fuerte competidor para cualquier país que pretenda participar activamente en el comercio internacional, como es el caso de México. De ahí que sea indispensable que ese enorme país se ajuste a las reglas del juego instituidas en esa materia.

Para China, su membresía al organismo la obliga a modificar muchos aspectos de su actual sistema de control, administración y fomento de las relaciones económicas con el resto del mundo. En consecuencia, tendrá que pagar los costos y no sólo recibir los beneficios; por lo pronto, se estima que el enorme superávit en balanza en cuenta corriente con el exterior, que por muchos años ha tenido (característica sui generis para un país en desarrollo) declinará rápidamente como resultado de su mayor apertura comercial. Ese superávit fue de 35.4 miles de millones de dólares estadounidenses en 2002, se cree que bajará a 12.0 en 2003, y se estima que llegará a 5.2 mil millones en 2004 (EIU, junio, 2003:13).

Por su parte, México tiene que revisar su política económica si quiere seguir compitiendo internacionalmente y aprovechar nuevos mercados, entre los que estará, sin duda alguna y en volúmenes significativos, el chino. Además, su cercanía al más atractivo del mundo, el de América del Norte y la abundancia de mano de obra relativamente barata han dejado de representar una ventaja comparativa, por lo menos frente a China. 


\section{Bibliografía}

Algieri, Franco, "EU Economic Relations with China: An Institutional Perspective", The China Quarterly (CQ), núm. 169, marzo 2002, pp. 6477.

Anguiano, Eugenio et al., China contemporánea. La construcción de un país (desde 1949), México, El Colegio de México, 2001, 453 pp.

Agrawal, Pradeep y Pravakar Sahoo, "China's Accession to WTO. Implications for China and India", en Economic and Political Weekly, núm. 25, vol. XXXVIII, 21-27 de junio, 2003, pp. 2544-2551.

Banco Mundial (Grupo del) en www.bancomundial. org, estadísticas comerciales, económicas y financieras.

Dam, Kenneth W., The Rules of the Game. Reform and Evolution in the International Monetary System, Chicago y Londres, The University of Chicago Press, 1982.

De la Calle, Luis, "China en la oмc. Espejo para México", Foreign Affairs en español, otoñoinvierno de 2002, pp. 152-161.

DeWoskin, Kenneth J., "The wTo and the Telecommunications Sector in China", China Quarterly (CQ), núm. 167, septiembre 2001, pp. 630-654.

Economist Intelligence Unit (EIU), Country Profile 2003, China, uK, 2003.

- Country Report, March \& June 2003, China, UK, 2003.

EU in the World, "Highlights of the EU-China Agreement on wTO", en europa.eu.int/comm./ trade/bilateral/china/high.htm, 19 de mayo de 2000.

Far Eastern Economic Review (FEER), 5 de diciembre 2002 , pp. $30-33$ y 2 de octubre de 2003 , pp. 2628.

Fewsmith, Joseph, "The Political and Social Implications of China's Accession to the wTO" China Quarterly (CQ), núm. 167, septiembre 2001, pp. 573-591.

Fondo Monetario Internacional (FMI), World Economic Outlook, April 2003. Growth and Institutions, Washington DC, 2003.

González García, Juan y Carlos Gómez Chiñas, "Apertura económica en China y México", en Revista Comercio Exterior, Banco Nacional de Comercio Exterior, S.N.C., núm. 11, vol. 49, noviembre 1999, pp. 991-1004.

Harwitt, Eric, "The Impact of wTO Membership on the Automobile Industry in China", China Quarterly (CQ), núm. 167, septiembre 2001, pp. 655-670.
Instituto Nacional de Estadística Geografía e Informática (INEGI), México, 2003, en www.inegi. gob.mx, información estadística.

Jiang Zemin "China's wTo Membership Benefits All”, resumen del discurso del presidente de la República Popular China, señor Jiang Zemin, en la sede de la embajada de su país en Washington, E.U., 15 de mayo de 2001, en www.chinaembassy.org/eng/10465.html

Keesing's. Record of World Events, 1995 y 1999.

Langlois (Jr.), John D., "The wTo and China's Financial System" China Quarterly (CQ), núm. 167, septiembre 2001, pp. 610-629.

Lardy, Nicholas R., Integrating China into the Global Economy, Washington DC, Brookings Institution Press, 2002.

McKinnon Ronald I., The Rules of the Game. International Money and Exchange Rates, The Massachusetts Institute of Technology (MIT) Press, Cambridge, Mass, 1996, 528 pp.

Orrego Vicuña, Francisco (compilador), Derecho Internacional Económico, I. América Latina y la cláusula de la nación más favorecida, y II. Las nuevas estructuras del comercio internacional. México, Serie Lecturas, El Trimestre Económico, núms. 10* y 10**, 247 y 391 pp., respectivamente, FCE, 1974.

Potter, Pitman B., "The Legal Implications of China's Accession to the wTO" China Quarterly (CQ), núm. 167, septiembre 2001, pp. 592-609.

Secretaría de Economía, Dirección General de Asuntos Comerciales Multilaterales, "China, comercio e inversión con México”, presentación en Power Point, México, 2002.

[Grupo de trabajo:] Secretaría de Hacienda y Crédito Público, Banco de México, Secretaría de Economía e Instituto Nacional de Estadística, Geografía e Informática, México, 2003, en www.inegi.gob.mx

United Nations Conference on Trade and Development (UNCTAD), Division on Investment, Technology and Enterprise Development, World Investment Report 2003. FDI Policies for Development: National and International Perspectives, publicación de la ONU, núm. E.03.11.D.8, Nueva York y Ginebra, 2003, en www.unctad.org

United Nations, Executive Board of the United Nations Development Programme and of the United Nations Population Fund, First Country Cooperation Framework for the People's Republic of China (1996-2000), UNDP: Country Cooperation Frameworks and Related Matters. 
DP/CCF/CPR/1, Nueva York, E.U., 8 de julio de 1996.

, "Letter Dated 19 November 2001 from the Permanent Representative of Qatar to the United Nations addressed to the Secretary-General", Document A/C.2/56/7, onU, Nueva York, 26 de noviembre 2001.

(The) White House Office of Public Liason, EE.UU., "Summary of us-China Bilateral wTo Agreement", Briefing on the Clinton Administration Agenda for the World Trade Organization Material, 17 de noviembre 1999, en www.uschina.org/public/991115a.html

Williams, Brett y Deborah Cass, China's Accession to GATT and the Control of Imports of Goods by State Trading Enterprises in China, China and the wTo Working Papers 2000/1, The Australian National University, Faculty of Law, Australia, 2000, 29 pp.

Wong, John, Yinhua Mai y Qi Luo, Sino-Us Trade Accord and China's Accession to the World Trade Organization, East Asian Institute (EAI), National University of Singapore, Contemporary China Series, núm. 27, World Scientific, Singapore, Singapore University Press, 2000. $60 \mathrm{pp}$.

World Almanac Books, The World Almanac and Book of Facts 2003, World Almanac Education Group, Inc., E.U., 2003
(The) World Bank, China Engaged. Integration with the Global Economy ( Cuaderno Anexo a China 2002). Development Challenges in the New Century, Washington DC, 1997.

, World Development Indicators 2001. Washington DC, 2001.

(The) World Trade Organization (wTO), "China's Accession to the WTO and its Relationship to the Chinese Taipei accession and to Hong Kong and Macau, China", nota sobre la historia de la relación de China con el GATT y la OMC, marzo de 2001, en WWW.wto.org

- WTO/GATT Members, página actualizada a abril de 2003, en www.wto.org/english/thewto_e/ gattmem_e.htm

, Ministerial declaration (punto 9), adoptada en Doha, Qatar el 14 de noviembre de 2001, en www.wto.org

Yamazawa, Ippei y Ken-ichia Imai (compiladores), China Enters WTO: Pursuing Symbiosis with the Global Economy, Papers and Proceedings of the International Symposium on China Enters wTO: publicación del Institute of Developing Economies, Japan External Trade Organization, Japón, 2001, 187 pp. 